\title{
Da prescrição da sentença e sua execução
}

\author{
S. Soares de Faria
}

$10^{\circ}$ - No direito romano Justiniano já a litis contestatio desaparecera, esvanecendo-se, á medida que se operavá a transformação no processo civil romano, e se chegava á terceira fase - a das extraordinaria cognitioneś. E com ela, os efeitos que, nos períodos anteriores, se justificavam, embora, ainda hoje, suscetiveis de dúvidas e de discussões interminaveis. E' verdade que alguns processualistas porfiam em sustentar a subsistência desse ato, mesmo neste último período, divisando na Lei $35 \S 1 \mathrm{D}$, de auro legato, 34, 2, uma prova claríssima da sua subsistência no direito Justiniano. É a lição de Bethmann Hollveg, Zivilprozess, como é a de Keller, Prozess, § 81 e Wiedring, Kirk Viertelyahrsschrift, XXI, p. 268, como se vê em GLück, notas ao Livro V, T. I, $\S 499$.

$2 .^{\circ}$ - Seja como for, admitida a sua existência na última fase, é certa e indiscutivel a profunda transformação operada, porque já não aparece como ato formal e solene, confirmatório da instrução do Juizo, e destinado a provar in judicio quanto se passara in jure ou exsurgindo, no período formulário, quando as partes recebiam a formula, que as trasladava in judicio. No período da extraordinaria judicia, a 1. c. já se não apresenta como ato formal e solene, mas como puro ponto ideal, resultante da disputa liminar entre as partes - post narrationem propositam et contradictionem objectam (L. 14 I $\mathrm{C}$ de ind. 3,1 ) que levava ao espírito do juiz uma idéia clara do preciso objeto da controvérsia, se- 
gundo Buonamici, citado por Brugi, nos comentários ao precitado passo de GLÜck. Essa a comunis opinio, muito embora, com fundamento na $\mathrm{L}$. I $\mathrm{C}$ de litis contest., tivesse Wiedring divisado a sua formação no momento em que começava a narração do negócio - narratio negotti.

3. - A essa afirmação revidam os partidários da opinião primeiramente exposta, mostrando que esta última constituição punha a mira tão sómente em distinguir a editio actionis da litis contestatio, e que a palavra narratio compreende também a responsio do Réu. efeitos,

$40^{\circ}$ - Mas é indubitavel que quanto aos seus primeiros consumptio actionis perpetuação da ação interrupção da prescrição,

mesmo que seja admitida, deles aparece inteiramente despojada. O ef eito consuntivo da ação, que levava á destruição material do direito pleiteado em juizo, dando nascimento a um direito novo, é fenômeno que Keller denomina função positiva da l. c., em contraposição á função negativa que era o impedimento de agir de novo em juizo, não chegara até o direito justinianeo. Embora BECKER e outros a contestem, a lição de Savigny é irrespondivel. O desaparecimento dessa idéia é a melhor demonstração de que, na extraordinaria cognitio, se havia perdido o conceito clássico da litis contestatio. E com ela subvertera-se o ef eito novatório, pois, nesse período, na afirmação de Wenger, "non c'e piú un atto institutivo della lite che annullasse il debito per una prestazione di diritto privato e collocasse al suo posto in virtù di una novazione processuale un condemnari oportere" (LEOPOLD Wenger, Instituições, § 28).

$5 .^{\circ}$ - A interrupção da prescrição já não é efeito da litiscontestação, mas do início da ação, e a perpetuação da ação, a que aludem os textos e se reportam os comentadores, 
pelo tempo de 30 anos, pela Const. de Teodoro in e de 40 pela Justiniano, é ponto que, em Direito Romano, exige e reclama a maior atenção. Embora ao arrepio da comunis opinio, é digna de acatamento a opinião de VoET que a não admite, por ter sido aquele prazo limitado a três anos, por fôrça da constituição, muito discutida - lex properandum - denominação que lhe adveio da palavra inicial, e que não permitia que as ações se procrastinassem a excedessem á vida humana - non ultra metas post litem contestatam esse protrahendas (Cod. III, 1, 13, 1).

$6 .^{\circ}$ - A conceituação, no entanto, da litis contestação como um contrato, produtor de novação, novação necessária, novação dupla, que podia ajustar-se no primitivo processo romano, mas já duvidosa no seu último período, bem como a perpetuidade das ações dela decorrentes, que o espírito dominante, nesta última fase repelira, entrou a ser o tormento dos juristas. A confusão de noções, peculiares a cada fase, produziu a transplantação para o direito moderno, de idéias já esvaecidas no direito de Justiniano e que não mais se adequavam ás modificações porque havia passado o instituto da l. c., a ponto de chegar a Justiniano inteiramente vasio de sentido.

7. - Assim, é que, no Direito Português, as Ordenações Manoelinas deram á l. c., a figura formal de ato inde- · pendente, consubstanciando-a num termo de processo em que o R. negava o direito do A., ou narrava o fato, exclusivo de tal direito. Depois é que vinha a contrariedade (Livro 3. T. 39). E passavam a atribuir-lhe os mais variados efeitos, muitos dos quais já o direito de Justiniavo não mais lhe reconhecia. A inutilidade do instituto, que as Ordenações Filipinas admitiram e consagraram, fora divisada pelos autores do Reg. 737, que o não contemplaram. O espírito arguto de Paula Batista a ele não se referiu, por não considerar a l. c., cousa diferente da contrariedade das ações ordinárias ou da contestação ou embargos das ações sumárias. 
8. ${ }^{\circ}$ - Quanto á perpetuação da ação, com fundamento nas constituições de Teodoro e Justiniano, que o direito reinícola consagrara, a despeito da Lex Properandum, é ponto que hoje devia ser considerado extreme de qualquer duvida, em face do Código Civil, que não reconheceu tal perpetuidade. Um tal ef eito desapareceu com o Reg. 737, nas causas comerciais e nas civis, por fôrça do art. 1.807 do C. Civil.

9. - De tal sorte e na realidade, a única função atribuivel hoje á l. c., é a de fixar o litígio, determinando com precisão o ponto ou os pontos, que constituem a relação jurídica objeto da sentença e fixando as lindes, que o seu prolator não poderá ultrapassar. Atingido um tal momento, determinado estará e sem possibilidade de alteração o objeto da demanda.

10. - Perdidos os efeitos novatórios, inadmissivel o carater contratual ou de quasi contrato, que só poderiam ser compreendidos e justificados na contextura do primitivo processo romano, perdida para a citação outras valiosas consequências, a l. c., teria desaparecido inteiramente, si não fora o efeito processual que lhe sobrou, qual o de não permitir que a posição das partes se altere ou se modifique, de forma a produzir-se inovação no feito.

11. - Mas, si não existe mais a consumptio actionis, si a novação, necessária ou não, simples ou dúplice, não mais existe, por incompativel com o direito atual, também se não justifica a doutrina do efeito novatório da sentença. Do mesmo modo que não ha novação, com o início da lide, também tal fenômeno se não opera com a sentença.

Essa verdade, proclamou-a o anotador de Windscheid, nestes conceitos lapidares:

"Il rapporto, su cui cade la sentenza, non solo no viene meno per el passagio di questo in giudicato, ma per di più ha una esistenza, che oramai 
è coperto di ogni attaco. E nessuno vorra sostenere che un diritto vien meno solo perchè acquista una maggior vigoria. Il titolo fondamentale $\dot{e}$ sempre il diritto fatto valere. Dopo la sentenza non si può riporre in discussione da alcuna parte il diritto da essa acertato, como non si potnebbe far valere il diritto da essa negato. Ma da ciò non deriva che la sentenza escluda l'antico titolo, e gli sostituisca un titolo nuevo per sé stante. Il vero è anzi che la sentenza produce il suo effetto in quanto appunto accerta l'esistenza del titolo".

12. - Assim é incontestavel que da sentença não exsurge um direito novo, mas nela persiste o direito pleiteado, já agora reconhecido e revigorado. A eficácia formal do julgado, a sua verdade indiscutivel consiste, justamente, na afirmação do direito precedente. Certamente, dora em deante, continua o douto comentador a Windscheid,

"non si ha più bisogno di recorrere al titolo antico: ma solo nel senso che la sentenza basta a documentare I'esistenza, che non se deve più discuterne. Ma quanto agli effetti pratici, il titolo è sempre decisivo e tutto si comisura alla sua stregna". $(4,722)$.

13. - A sentença, nos dois primeiros períodos do processo romano, pela natureza privada do juiz que a proferia, assemelhava-se a um parecer, dava nascimento a uma obligatio, é á ação correspondente para obter seu cumprimento. No processo clássico, o vencedor não tinha outro remédio que não a actio iudicati para promover o cumprimento da obligatio. A sentença dava origem áquele vínculo obrigatório, protegido pela actio correlativa, na lição de Bethmann HoLLVEG (Rom. Zivilprozess, III, 296). Mas já nas cognitiones extra ordinem, a execução podia ser ordenada pelo magistrado, com um simples pedido unilateral, na opinião de Eisele, 
no seu "Abhandlungen Zum Rom. Zivilprozess", pg. 125, com fundamento no fr. 50, D. 21, 2 e fr. $74 \S \mathrm{I} D, 21,2$.

14. - Mas no processo extra ordinem, não se fundando mais a sentença na litis contestatio, mas no poder de julgar que o juiz recebe diretamente da lei, perdeu a actio iudicati essa função protetora da obligatio. Si no período formulário, não tinha função executiva, pois actio iudicati e execução não se confundiam, por serem institutos distintos, tambem no direito post classico e Justinianeo não lhe póde ser atribuida essa função, porque a execução pela autoridade pública, por via direta e continuativa da ação, determinara o seu desaparecimento ou absorção.

E verdade que os textos ainda falam de actio iudicati, mas não mais lhe dão aquela fisionomia de ação autônoma, das épocas anteriores, outra coisa não representando senão o direito que tem o vencedor de obter a execução coativa da sentença. A antiga termintologia sobreviveu ao desaparecimento da função primacial e típica do instituto, sofrendo, porém, aquela transformação de conteúdo que era imposta pela evolução histórica no sentido do carater essencialmente publicístico da jurisdição (Brondo Brondr, in "Studii in onore di P. Bonfante", IV, 19). Execução e actio iudicati se confundiram, esta por aquela absorvida, como resultado da unificação de poderes, na pessôa do mesmo juiz, que julgava a causa e ordenava a execução, impossivel no sistema da ordo indiciarum privatorum, mas perfeitamente aceitavel na organização judiciária de Justrniano, in verbis legitimam viam contra reo contumacis aperire.

15. - No nosso direito, a sentença não se executa pela actio iudicati. Esta ação, que tinha sua razão lógica no direito romano antigo e que depois ali mesmo desapareceu (JoÃo Monteiro, $\S 272$ ), assumiu nova feição, em face das Ord. III, $25,8 .^{\circ}$, que configura a unica hipótese de sua sobrevivência, entre nós. Só se emprega, quando da sentença nasça ação, o que não é mesmo que dizer que de toda sentença nasce 
ação. A actio iudicati seu in factum é apenas um obseletismo romano, no dizer do grande jurisconsulto no $\S$ invocado, como já ficou que farte demonstrado. Que nem de toda sentença nasce ação, proficientemente o demonstrou GoMEs, no seu "Manual Pratico", VLI, com argumentos irrespondiveis. A erronea interpretação em contrario provém de CALDAS, que se enganou, e os mais foram seguindo sem exame, como ás vezes sucede, imitando as aves, pois quando uma vôa as outras a seguem (JoÃo Monterro, $\S$ citado).

17. - Não se póde, pois, considerar a execução uma ação ou um instituto autônomo. O Estado reconhece o direito e coage o vencido a satisfazer a sua obrigação. A execução é a mesma ação no seu desenvolvimento final, última cena do mesmo drama judiciário. Propondo a ação, o A. não pretende apenas o reconhecimento platônico do seu direito, mas deseja que a tutela jurídica, que invoca, seja eficiente e completa. Não póde se esvair com a sentença, que é mera estação no processo. Atingida esta, que não é fịm mas meio, passa-se á execução. Não ha duas ações autônomas, mas dois momentos de uma só ação, pois, na lição do comentador WINDSCHEID,

"la procedura di cognizione e quella di esecuzione non sono se non aspetti o momenti diversi di quest'unico rapporto. L'actio, como jus persequendi iudicio quod sibi debetur, non implica solo l'acertamento del diritto, ma tutto il complesso dei mezzi attraverso $i$ quali la ragioze privatà giunge a soddisfarcimento per autorità di Stato" (IV, 723).

E conclue com afirmar, invocando FADDA, que o procedimento é uma unidade resultante de uma série de atos,

"que appunto lo scopo unifica", 
pois já na definição romana o persequi, que, como é sabido, designa o procedimento executivo,

"accena a questa unitá compreendente anche l'esecuzione".

18. - A execução constitue uma parte do exercício da ação, não podendo ser recebida, em face do exposto, a lição dos que, como Mortara, nela divisam "um organismo processual autônomo". Nas ações de condenação a função jurisdicional não se extingue com a sentença. A prestação não está inteiramente satisfeita e só se completa com a satisfação do julgado, a que tende a ação intentada.

Existe uma unidade que liga as duas fases de uma só ação, unidade ideal, na expressão de DE Palo, unidade concreta, unità degli intenti, no dizer de Mortara, que, ao revez do que sustenta este ilustre processualista, impede o atributo de autonomia que se lhe pretende concedr. São, na justa comparação do msmo autor,

\section{parti di un mecanismo,}

mas de um só mecanismo, que é a açã̃o, no seu dúplice intento, obter a condenação e efetivá-la.

Expressivas são estas palavras do notavel Professor Ugo Rocco:

"Mentre infatti per le azioni di acertamento la sentenza è fine a se stessa, nella azioni di condana la sentenza non è che il punto di passaggio tra il giudizio e l'esecuzione.

E poichè la pretesa giuridica individuale alla condamna non consta soltanto della pretesa alla sentenza di condana ma anche di una pretesa alla esecuzione, cosi il passaggio in giudicato della sentenza di condana rappresentarà un adempimento parziale dell'azione di condana, la quale resterá in vita per quella parte che non essendo 
ancora soddisfatta, puó ancora esercitarsi" (Ugo Rocco, "Diritto Processuale Civile", pg. 383).

A unidade é hoje indiscutivel no nosso direito, deante do disposto no nosso Código de Processo Civil, em face do qual so ha uma instancia, que se inicia com a citação e termina com execução da sentença.

19. - Ora si ação e execução se confundem, esta como mera fase daquela, si a sentença não forja um novo direito, mas apenas consagra o direito preexistente, é desarrazoado pretender tratamentos diversos, no que tange à prescrição: um para o direito anterior á sentença, outro para o mesmo direito, que esta reconheceu e afirmou. Si a relação jurídica permanece íntegra, apenas revestida da fôrça que lhe advém da sentença, não transmuda nem se metamorfoseia. A sentença não a modifica na substância, embora lhe conceda a força coativa do Estado para a sua efetivação. E idêntica a si mesma, antes e depois de reconhecida.

20. - Assim, não é possivel cogitar de uma prescrição especial para a sentença, que a nossa lei civil não admitiu. A prescrição da sentença é a mesma da ação, em que ela foi proferida. Nem falar-se de prescrição diversa para a execução, por não ser esta, com já se demonstrou, senão a mesma ação no seu final desenvolvimento.

Si a lei quisesse atribuir uma vida mais longa ao direito proclamado e reconhecido na sentença, teria manifestado claramente a sua intenção, como o fez o legislador alemão, não inteiramente libertado da influência romanística, e teria estatuido no sentido do art. do C. C. Alemão.

21. - Estatuindo o Código Civil Brasileiro que prescreverá em cinco anos toda e qualquer ação contra a Fazenda Federal, Estádual ou Municipal, e o Decreto lei n. 20.910, desenvolvendo o preceito, dispondo que ele abarca não só 
qualquer ação, como ainda qualquer direito, cessada deve estar a disputa entre os doutos, quanto ao alcance do $\mathrm{n}$. VI do $\S 10$ do art. 178. Não só as dívidas passivas, em tal privilégio se incluem, mas todo e qualquer direito e ação.

22. - Mas este diploma modificou a legislaçã́o, no tocante á interrupção-da prescrição, que não mais póde ser feita indefinidamente. A interrupção da prescrição, por qualquer de suas fórmas, só póde ser feita uma vez, e o prazo prescricional não se contará por inteiro, mas tão só pela metade.

Assim, sendo a prescrição de cinco anos, uma vez interrompida, começará a correr pela metada, isto é, o novo prazo não excederá a dois anos e meio.

23. - Nessa conformidade, interrompida, a prescrição, com a citação para a ação, e perdurando a instância, o prazo prescricional só começará a correr de novo, após o último áto praticado no processo, que, na hipótese da consulta, foi a sentença da superior instância, transitada em julgado.

0 art. 9 do Decreto 20.910, de 6 de janeiro de 1932, não admite a menor dúvida quanto:

a) só permitir uma interrupção;

b) reduzir pela metade o prazo prescricional após a interrupção;

c) oferecer duas modalidades para o início da contagem do prazo primitivo, assim mutilado, ou seja;

d) da data do áto interruptivo ou;

e) do termo do respetivo processo.

24. - A interrupção póde operar-se por fôrça de um processo especial ou em consequência da citação inicial, sabido como é que esse é justamente um dos efeitos de tal citação (n. V do art. 166 do C. P. Civil).

Uma vez, pois, que a ação se desenvolve o efeito interruptivo da citação se protrai até o último ato que no pro- 
cesso for praticado. Si este ato foi a sentença, dela se começará a contar o novo prazo. Vale dizer que, enquanto viva a instância, pela sua constante movimentação, ñ̃o correrá o novo prazo. Mas, decorridos dois anos e meio, após a sentença, sem que nenhum outro ato haja sido praticado, consumou-se a prescrição de qualquer direito e ação, e,

logo, o direito de promover a execução.

25. - Nem se diga que esta interpretação leva a um absurdo qual o de dar a um direito já reconhecido menor proteção que a concedida ao ainda não revestido da força que lhe advem de uma sentença favoravel. Não ha tal. Primeiro, porque os termos da lei não permitem outra inteligência. Segundo, porque ela é a unica que com o seu espírito se coaduna.

Em verdade, o decreto-lei n. 20.810, de 6 de janeiro de 1932, pôs a mira em evitar as procrastinações decorrentes de interrupções sucessivas, que tornavam eternamente em suspenso as pretensões contra o Estado, e em obrigar os postulantes a objetivá-las, propondo as ações e dando-lhes contínuo andamento, afim de serem logo resolvidas.

Esses objetivos não pódem ser censurados, tanto mais quanto o legislador não determinou o reinício do curso prescricional do ato interruptivo, mas do ultimo ato no processo praticado. A proteção é a mesma quer antes, quer depois da sentença.

26. - Isto posto, em face dos princípios e regras expostos que servem de supedâneo ás conclusões, afirmamos:

a) não existe, no nosso direito, prazo especial para a prescrição das sentenças;

b) a prescrição é a mesma da relação jurídica nela resolvida;

c) si por hipótese for de cinco anos, e tendo sido interrompida por força de ação judicial, esse prazo ficará reduzido a dois anos e meio. 